\title{
Wayfinding Systems in Educational Environments
}

\author{
Shireen Kanakri ${ }^{1, *}$, Megan Schott ${ }^{2}$, Amy Mitchell $^{3}$, Haitham Mohammad ${ }^{4}$, Minna Etters ${ }^{1}$, Nicole Palme ${ }^{1}$ \\ ${ }^{1}$ Department of Family and Consumer Science, College of Applied Technology, Ball State University, USA \\ ${ }^{2}$ Department of Psychological Science, Ball State University, USA \\ ${ }^{3}$ Department of Counseling Psychology and Guidance Services, Ball State University, USA \\ ${ }^{4}$ Department of Electrical Engineering, Texas A\&M University, USA
}

Copyright $(2016$ by authors, all rights reserved. Authors agree that this article remains permanently open access under the terms of the Creative Commons Attribution License 4.0 international License.

\begin{abstract}
Wayfinding is the phenomenon of locating an intended destination within an environment [1]. This occurs through complex, dynamic communication between the built environment and the user [2]. Successful wayfinding design allows users to: determine their location within a setting, determine their destination, and develop a plan that will take them from their location to their destination. This study analyzes the role of stress in wayfinding, and the implications of this relationship for educational wayfinding systems. Thirty-five participants were assigned target locations in two buildings. Wayfinding routes were mapped and timed by research assistants. After the tasks, participants completed measures of stress level and difficulty. Results supported the hypothesis that perceived difficulty is positively correlated with level of stress. The implications of these findings are discussed in relation to effective wayfinding systems in education settings.
\end{abstract}

Keywords Wayfinding, Education, Stress

\section{Introduction}

Wayfinding is broadly defined as finding an intended destination within an environment [1]. Although a simple concept, understanding, refining and optimizing wayfinding is complex and multifaceted [2,3]. This is accomplished through an interaction of individual ability and environmental cues [4]. Environmental information should offer cues to wayfinding [5] although different users may perceive these differently. Although some universal principles apply across settings, some wayfinding concepts and details may be setting-specific.

\subsection{Wayfinding Concepts}

Wayfinding may be accomplished by a number of methods. Reliance on maps and written directions, verbal explanations of directions, visual cues such as landmarks, colors, and other remarkable features, and personal interaction with a guide are common wayfinding tools [6]. A number of frameworks have been developed to conceptualize and study wayfinding. Most agree that successful wayfinding systems allow users to: 1) determine their location within a setting, 2) determine their destination, and 3) develop a plan that will take them from their location to their destination [7]. Successful wayfinding systems are made up of a series of identifiers: 1) identification and marking of spaces, 2) grouping spaces, and 3) linking and organizing spaces through both architectural and graphic means [7]. Different types of wayfinding, such as emergency, resolution, or recreational wayfinding, may rely on different wayfinding strategies [3], although ultimately many of the design principles of wayfinding are universal. "Clear circulation and consistent and easily read signage should be easily seen and understood amidst conflicting or distracting sights or sounds. In all cases, clarity of direction from the viewer's changing perspective is the guiding criterion in designing circulation for ease of orientation and wayfinding" [8].

Graphic information systems such as signs and maps complement the environmental design system [9]. Signs may provide direction, identification, orientation, or regulation [10,11]. Notably, Butler, Acquino, Hissong, and Scott [12] found that signs were more efficient than you-are-here maps or spoken instructions provided by staff in the building. This appeared to occur for two reasons. First, verbal instructions rely on both the abilities and investment of the one providing instructions, and the ability of the wayfinder to remember and execute the instructions. Second, wayfinders using signs found their destinations fastest because signs provide directions at key locations without requiring the user to memorize directions. Thus, signs save time through avoiding time spent studying a map, memorizing and remember directions, as well as decreasing the number of wrong turns and hesitation at decision points [12]. This study highlights the importance of an effective wayfinding signage system in education settings to increase effective wayfinding and decrease staff and student frustration. 


\subsection{Public Wayfinding Systems}

Most wayfinding research in design has been conducted in healthcare settings. This research is vital to both maintaining the healthy functioning of the hospital and keeping patient stress to a minimum $[4,6]$. In medical settings, good wayfinding promotes reduction of stress, functional efficiency, visitor accessibility, safety, user empowerment, and an improved bottom line [6]. One hospital art program selected unique art motifs for each floor/department as an effective visual method of identification [6]. Furthermore, each art theme was selected to be representative of healing narratives for that area. Research on this approach indicated architectural and interior design features that provided intuitive pathways, the art program providing landmarks and a meaningful sense of place, and a clear signage system with wayfinding information, easy-to-read graphics, and hospital branding, in addition to maps were the beneficial wayfinding elements within the hospital [6]. Hospitals have received a great deal of attention as a location where effective wayfinding design may decrease user stress.

Wayfinding in airports and other public transit structures is essential to the smooth flow of traffic, and thus a major focus in the development and construction of airports. The Airport Cooperative Research Program (ACRP) has provided an extensive report on wayfinding and signing guidelines [13]. This is a comprehensive document offering wayfinding strategies for each aspect of the airport, including roadways, parking, curbside and ground transportation, the terminal, technology, and regulatory and information signs. The airport is an example of the multifaceted aspects of wayfinding, as many different people attempt to complete a variety of wayfinding tasks, sometimes within small amounts of time, and with varying levels of experience finding their way in airports [3]. Much attention has been given to wayfinding in airports, given the complexity of the challenges and the benefits of facilitating effective traffic flow in such a place.

\subsection{Wayfinding in Education Settings}

Limited empirical literature is available on wayfinding in educational facilities. A handful of studies have provided information on the design of settings for children. Read [5] sought to understand the use of color in childcare facilities to enhance wayfinding and support spatial orientation. Particularly new students, who may be acclimating to various aspects of academia will benefit from effective wayfinding environments. A study of how freshman found their way through a library to locate an assigned book provided recommendations about how sources of help and uniform signage improved wayfinders' experiences [14]. Li and Klippel [2] also conducted library wayfinding studies, identifying limited visibility, layout complexity, and familiarity with the space as essential elements to consider in this setting. In a study of a university in Ontario, $70 \%$ of those surveyed indicating accessing and navigating interiors was the most challenging wayfinding task on campus [9]. Specifically, locating classrooms was cited as the most difficult task. Students are most likely to complain about wayfinding for classrooms because they desire wayfinding be easy and efficient to avoid anxiety [15].

\subsection{Stress and Wayfinding}

Wayfinding occurs out of an interaction of spatial orientation, cognitive mapping, language, culture, gender and biology, as well as environmental factors such as layout complexity, paths, and signs [3]. Remarkably, a wayfinding study in an airport showed that human factors, such as cognitive skills, spatial skills and spatial anxiety, had a greater impact on wayfinding than the built environment did [3]. However, a confusing environment is also expected to impact stress levels, as wayfinding issues may result in stress, frustration, and time loss [1,16]. Alternatively, anxiety affects perceptive and cognitive abilities [17], and stress and frustration are linked to disorientation [18]. Effective wayfinding systems should reduce stress by creating environmental legibility [9]. While empirical evidence is available for the positive impacts of effective wayfinding systems in hospitals and airports, stress occurring as a result of wayfinding difficulties in educational settings is in need of further empirical exploration. Additionally, this research can provide information about the creation of effective wayfinding systems in education. Further research may identify those wayfinding solutions that are most essential and effective in wayfinding in educational facilities.

\subsection{Objective}

The present study seeks to understand wayfinding in university buildings. Given the health and mental stress impacts of wayfinding, establishing supportive wayfinding environments on college campuses has significant implications for the wellness and performance of students.

Our current objective is to study the impact of stress during wayfinding, and under which conditions the wayfinding task is considered difficult. Specifically, it is hypothesized that ratings of the difficulty of the task will be positively correlated with ratings of participants' stress levels.

\section{Materials and Methods}

\subsection{Participants}

A total of 35 students and faculty members participated in the study.

\subsection{Procedures}

Participants were taken to the Noyer Complex (Noyer) 
and Teachers College (TC) on the Ball State University campus. Participants were given a specific room as the wayfinding target in each building, with a maximum limit of ten minutes to find the goal. Specifically, in Noyer participants were asked to find room 206 and to find room 604 in TC. Participants were instructed not to ask for help, unless there was a desk or station with a paid attendant available. A research assistant mapped participants' times and routes for each wayfinding task (see Figures 1,2). Immediately following the task participants completed the visual analog scales indicating levels of stress and difficulty.

\subsubsection{Maps.}

Research assistants completed maps tracking the route of each participant in each building. Four codes indicate essential points along the way. A capital "S" denoted the start point, a capital "M" denoted "Looking for a Map", a "?" denoted "Confused or Lost" and "E" marked the end point.

\subsubsection{Visual Analog Scales.}

The visual analog scales contain two (see Figure 3), face valid questions, "Please rate the level of difficulty from $1-10$," and "Please rate the level your level of stress in locating the target, from 1-10." Participants responded to both questions twice, once for the Noyer Complex task and once for the Teachers College task.

\subsection{Results}

Results include observer route maps (see Figures 1,2), comparisons of averages in the two wayfinding tasks, and (see Table 1), and Pearson correlations among the variables of interest.

The average amount of time it took to find TC 604 was 1 minute 48 seconds, while the average length of time to find Noyer 206 was 2 minutes 13 seconds. Participants exhibited an average of 0.86 point of confusion (don't know the correct direction) in TC, while only 0.57 in Noyer. Participants looked for a sign an average of 1.40 times in $\mathrm{TC}$, but only 1.26 times in Noyer. The average reported stress level for wayfinding in TC was 2.0, and 2.89 in Noyer. Participants reported an average difficulty of 2.74 in TC and 3.57 in Noyer (see Table 1). A related-samples t-test was conducted to analyze differences between results from TC and Noyer on each of the variables (time, stress, difficulty, confusion, sign). No significant differences were found.

Table1. Comparison of Wayfinding Locations by Averages

\begin{tabular}{ccc}
\hline & TC 604 & Noyer 206 \\
\hline Time & $1: 48$ & $2: 13$ \\
Confusion Points & 0.86 & 0.57 \\
Looking for Sign & 1.40 & 1.26 \\
Stress Level & 2.0 & 2.89 \\
Difficulty & 2.74 & 3.57 \\
\hline
\end{tabular}

Pearson correlation coefficients $(r)$ were calculated to test the association between each of the variables. The degrees of freedom associated with each test were 33 as calculated by $(N-2)$ where $(N)$ is the total sample size of each group. For the TC building, there was a significant positive correlation between stress and difficulty, $r(33)=0.90$, $p<.01$, stress and confusion points, $r(33)=.346, p<.05$, stress and the number of times a participant looked for a sign, $r(33)=.373, p<.05$, stress and time, $r(33)=.482$, $p<.01$, reported difficulty and time, $r(33)=.560, p<.01$, reported difficulty and confusion, $r(33)=.436, p<.01$, reported difficulty and the number of times a participant looked for a sign, $r(33)=.499, p<.01$, time and confusion points, $r(33)=.672, p<.01$, and time and the number of times a participant looked for a sign, $r(33)=.347, p<.01$.

For the Noyer building, there was also a significant positive correlation between time and stress, $r(33)=.615$, $\mathrm{p}<.01$, time and reported difficulty, $\mathrm{r}(33)=.741, \mathrm{p}<.01$, time and points of confusion, $\mathrm{r}(33)=.485, \mathrm{p}<.01$, stress and reported difficulty, $\mathrm{r}(33)=.817, \mathrm{p}<.01$, reported difficulty and points of confusion, $\mathrm{r}(33)=.431, \mathrm{p}<.01$, and points of confusion and the number of times a participant looked for a sign, $r(33)=.587, \mathrm{p}<.01$.

Results indicate that in general, as stress levels, points of confusion, difficulty levels, and number of instances the participant looked for a sign increase, the time to find the room increased in both TC and Noyer. In addition, as stress and difficulty levels increase, participants are more likely to look for a sign or exhibit points of confusion. In summary, consistent with our hypothesis, time, difficulty, and stress were positively correlated in these wayfinding tasks. 


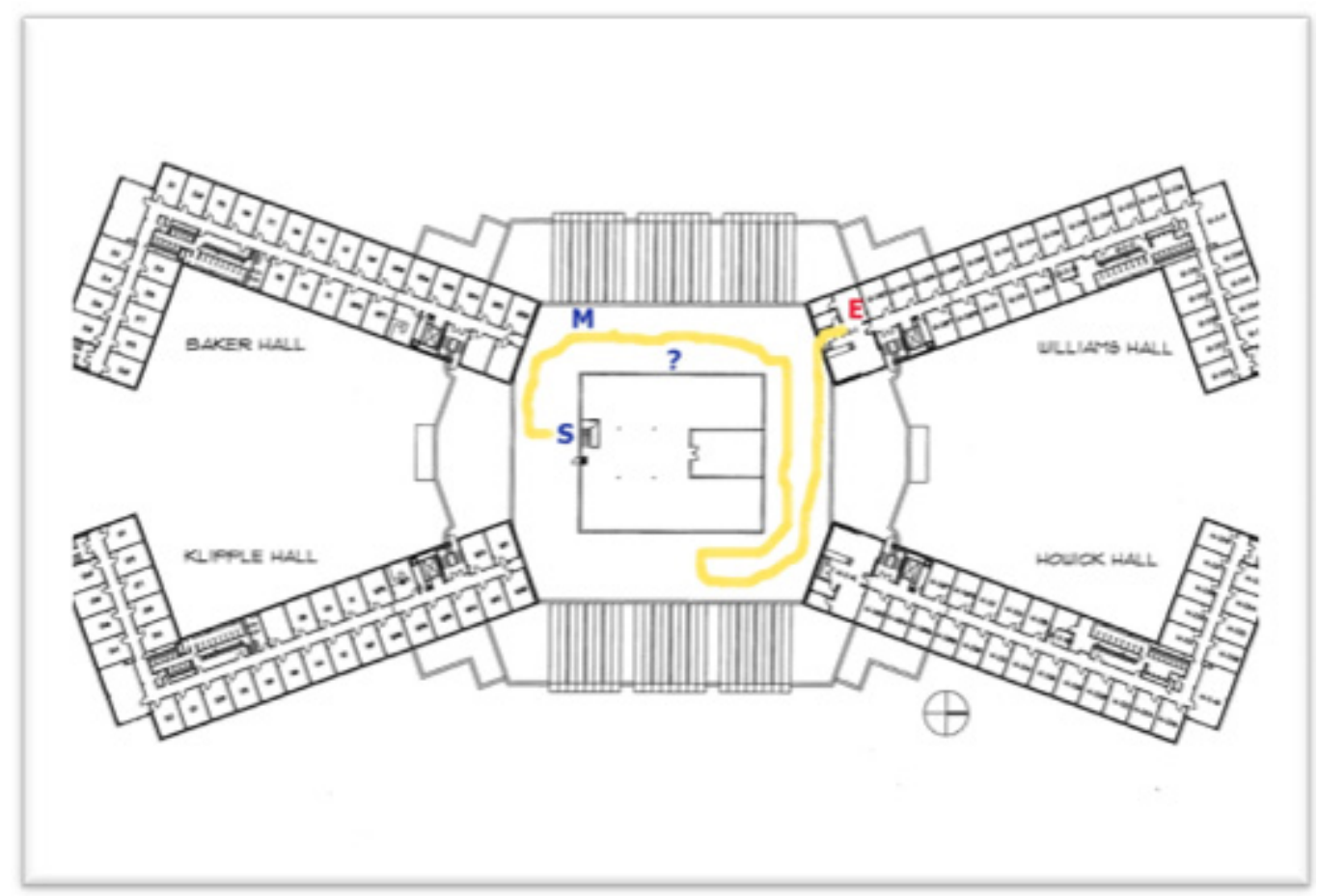

Figure 1. Noyer Hall floor plan with wayfinding path recorded

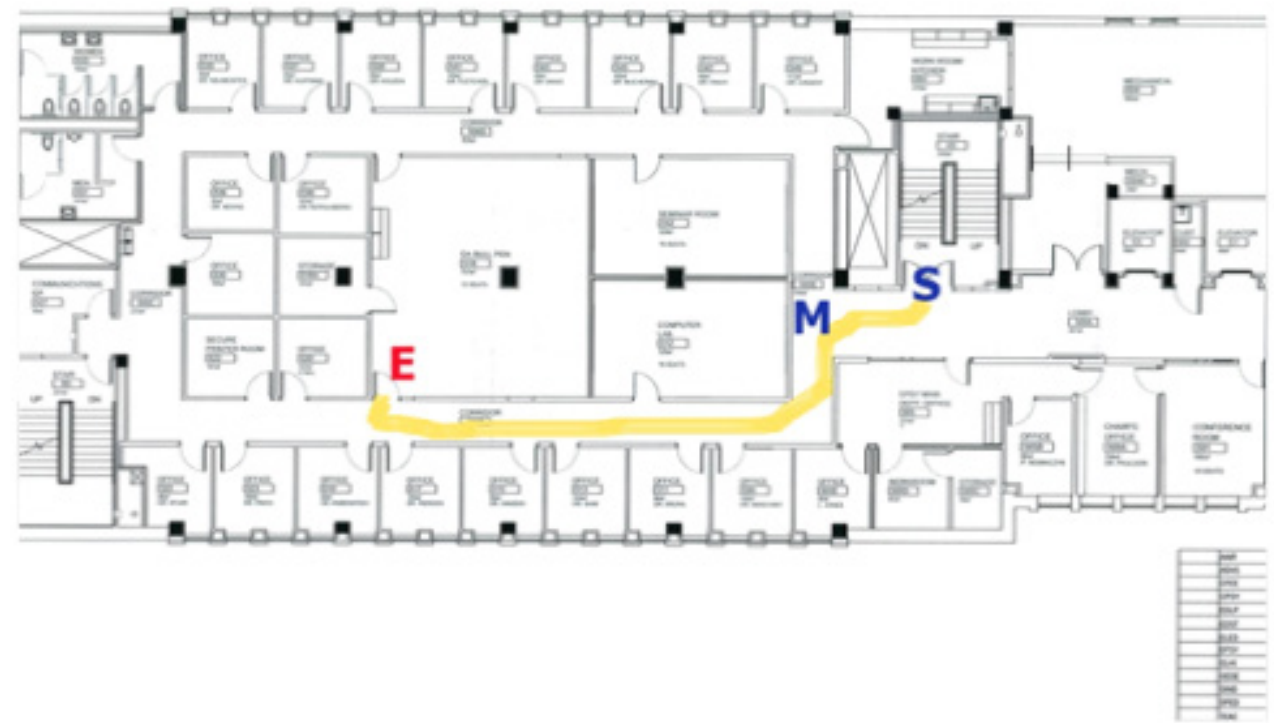

Figure 2. Teachers College floor plan with wayfinding path recorded 
Wayfinding System in an Educational Environment:

Name:

Time:

After completion the field tour, could you tell us about your experience?

- Define your levels of stress in Teachers college TC 604

\begin{tabular}{rrrrrrrrrrr}
0 & 1 & 2 & 3 & 4 & 5 & 6 & 7 & 8 & 9 & 10 \\
Nothing & \multicolumn{4}{c}{ Mid }
\end{tabular}

- Define your levels of difficulty in Teachers college TC 604

\begin{tabular}{lrrrrrrrrrr}
0 & 1 & 2 & 3 & 4 & 5 & 6 & 7 & 8 & 9 & 10 \\
Nothing & & \multicolumn{1}{c}{ Mid } & &
\end{tabular}

- Define your levels of stress in Noyer halls (H-201)

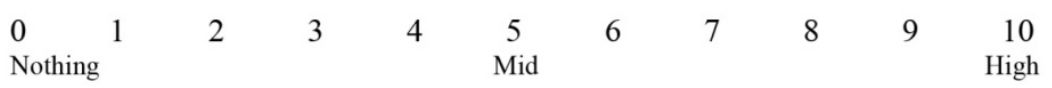

- Define your levels of difficulty in Nover halls (H-201)

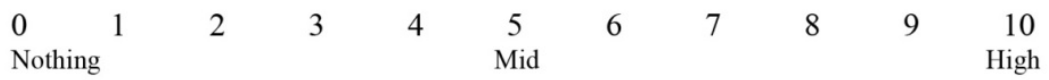

Thank you so much

Figure 3. The visual analog scales

\subsection{Discussion}

In an educational setting, finding both familiar and unfamiliar locations are frequent tasks for students, faculty, and staff alike. At the campus under study in the present research, classrooms are assigned by a computer system. At the start of a semester both students and faculty may have between two-four novel locations to find. The initial location of classrooms and other meeting places are likely to be somewhat anxiety provoking as both newcomers to the campus and seasoned students may experience stress when attempting to arrive on time to classes. Some difficult to find locations may continue to cause stress even as wayfinders become familiar with the routes they take to get there.

In this study, the wayfinding tasks were not statistically different in the time it took to locate the target destination, nor were they different in the level of stress and difficulty reported by participants. This is especially interesting given that the room in TC was four floors higher than the room in Noyer. This can be taken as evidence that having to ascend or descend floors academic buildings may not be a big issue for wayfinding. This may be because as in this study, floors in stairwells tend to be signed which has been shown in past research to facilitate wayfinding behavior [12]. This is supported by our finding that there were more significant difficulty related correlations with looking for a sign in TC (3) than in Noyer (1). This indicates that signs may be more 
critical for wayfinding in academic buildings with more floors.

In addition to an increased amount of sign looking, TC also showed a higher, though not significantly higher, amount of points of confusion compared to Noyer despite having a faster wayfinding time. This could be taken as evidence that additional floors of a building do not increase wayfinding time, but do increase the need for signs to facilitate wayfinding. Overall, this can be taken as evidence that when buildings are properly signed, increasing the amount of floors may not increase wayfinding time despite the increase in confusion it may cause.

The positive relationship between time and stress also partially supports the hypothesis that increased difficulty in wayfinding will also increase the subjective experience of stress. As stress was only measured using a one item questionnaire and no baseline measure was taken, it is difficult to attribute this increase in stress purely to participation in the study. However, these results may be taken as an indicator of an interactive effect between stress and wayfinding. Future studies may attempt to advance this research by measuring stress over time during complex wayfinding tasks.

\section{Conclusions}

In this study, wayfinding systems were found to differ between two academic buildings based primarily on the number of floors in the building. It was found that increasing the number of floors did not increase the total time needed for wayfinding. This is likely due to the increased number of signs that are present in stairwells which facilitate wayfinding. Future studies should focus on both the effects of stress over time during complex wayfinding tasks and should also systematically manipulate the complexity of the floorplan of the buildings and the number of floors in each building.

\section{REFERENCES}

[1] R. Passini, P. Arthur. Wayfinding: People, signs and architecture. McGraw-Hill Inc., New York, 1992.

[2] R. Li, A. Klippel. Wayfinding in libraries: Can problems be predicted? Journal of Map \& Geography Libraries, Vol.8. No.1, 21-38, 2012.

[3] A. Farr, T. Kleinschmidt, P. Yarlagadda, K. Mengersen. Wayfinding: A simple concept, a complex process. Transport Reviews, Vol.32, 715-743, 2012.
[4] J. Ahn. Wayfinding at the east campus of Cayuga Medical Center in Ithaca, NY. DEA 53 Project 2, fall 2006. Online Available:http://iwsp.human.cornell.edu/files/2013/09/Wayfi nding-at-the-East-Campus-of-CMC-2hds8uc.pdf

[5] M. Read. Use of color in childcare environments: Application of color for wayfinding and space definition in Alabama childcare environments. Early Childhood Education Journal, Vol.30, No.4, 233-239, 2003.

[6] B. Huelat. Wayfinding: Design for understanding. The Center for Health Design's Environmental Standards Council, 2007.

[7] S. Hunter. Design resources: DR-01 architectural wayfinding. Center for Inclusive Design and Environmental Access, IDeA Center, University at Buffalo, 1-7, 2010.

[8] R. S. Ulrich, C. Zimring, X. Quan, A, Joseph. The Environment's Impact on Stress. In S. Mayberry (Ed.), Improving Healthcare with Better Building Design, Health Administration Press, Chicago, 37-61, 2006.

[9] K. Oyelola. Wayfinding in university settings: A case study of the wayfinding design process at Carleton University. Ottawa, Ontario, 2014.

[10] M. A. Ford, D. Torok. Motivational signage increases physical activity on a college campus. Journal of American College Health, Vol.57, No.2, 242-244, 2008.

[11] D. Gibson. The wayfinding handbook: Information design for public places. Princeton Architectural Press, New York, 2009.

[12] D. Butler, A. Acquino, A. Hissong, P. Scott. Wayfinding by newcomers in a complex building. Human Factors, Vol.35, No.1, 159-173, 1993.

[13] Airport Cooperative Research Program (ACRP) report 52: Wayfinding and signing guidelines for airport terminals and landslide, 2011.

[14] J. Hahn, L. Zitron. How first-year students navigate the stacks: Implications for improving wayfinding. Reference \& User Services Quarterly, Vol.51, No.1, 28-35, 2011.

[15] L. Scott-Webber, M. Marini, J. Abraham. Higher education classrooms fail to meet needs of faculty and students. Journal of Interior Design, Vol.26, No.1, 16-34, 2000.

[16] G. W. Evans, J. M. McCoy. When buildings don't work: The role of architecture in human health. Journal of Environmental Psychology, Vol.18, No.1, 85-94, 1998.

[17] H. Xie, L. Filippidis, E. R. Galea, D. Blackshields, P. J. Lawrence. Experimental analysis of the effectiveness of emergency signage and its implementation in evacuation simulation. Fire and Materials, Vol.36, No.5-6, 367-382, 2012.

[18] H. Chang. Wayfinding strategies and tourist anxiety in unfamiliar destinations. Tourism Geographies, Vol.15, No.3, 529-550, 2013 